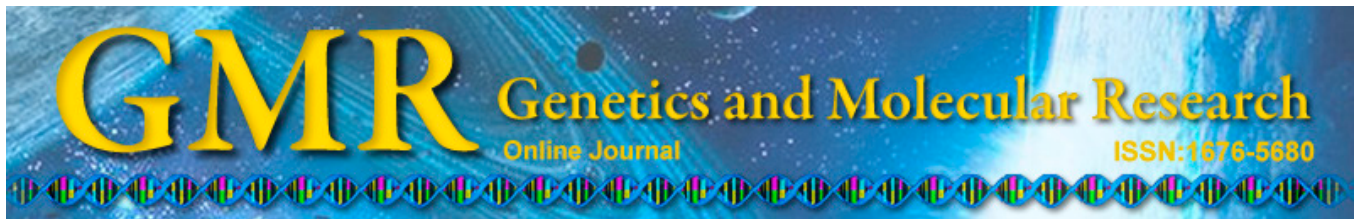

\title{
Phylogeographic analysis of African swine fever virus based on the $p 72$ gene sequence
}

\author{
Y. Muangkram ${ }^{1,2 *}$, M. Sukmak ${ }^{3 *}$ and W. Wajjwalku ${ }^{2}$ \\ ${ }^{1}$ Graduate School, Kasetsart University, Bangkhen Campus, \\ Chatuchak, Bangkok, Thailand \\ ${ }^{2}$ Faculty of Veterinary Medicine, Kasetsart University, \\ Kamphaeng Saen Campus, Nakorn Pathom, Thailand \\ ${ }^{3}$ Department of Farm Resources and Production Medicine, \\ Faculty of Veterinary Medicine, Kasetsart University, \\ Kamphaeng Saen Campus, Nakorn Pathom, Thailand \\ *These authors contributed equally to this study. \\ Corresponding author: W. Wajjwalku \\ E-mail: fvetwww@yahoo.com
}

Genet. Mol. Res. 14 (2): 4566-4574 (2015)

Received July 14, 2014

Accepted December 12, 2014

Published May 4, 2015

DOI http://dx.doi.org/10.4238/2015.May.4.15

\begin{abstract}
African swine fever virus (ASFV) outbreak has been considered as an emerging and re-emerging disease for almost a century. Diagnostically, simple polymerase chain reaction and sequencing-based molecular detection could be employed for both viral identification and genotyping. This study established a novel phylogenetic analysis and epidemiology comparison based on $205 \mathrm{bp}$ of $p 72$ gene sequences. Based on this partial $p 72$ fragment, an updated list of 44 different genotypes from a total of 516 ASFV sequences compiled from GenBank was generated. Nucleotide diversity was $0.04325 \pm 0.00231$. The analysis of spatial genetic variation divided the ASFV populations of the African continent into four clades (clade A: central and upper eastern Africa; clade B: eastern Africa; clade C: eastern and southern Africa; and clade D: southern Africa). These results and the developed protocol could serve as useful molecular tools for ASFV diagnosis from degraded DNA or putrefied samples, and also
\end{abstract}


provide the phylogeographic perspective to identify the origin of viral outbreaks, facilitating the decision planning to limit their spread.

Key words: African swine fever virus; Asfarviridae; B646L; Phylogenetic analysis

\section{INTRODUCTION}

African swine fever (ASF) outbreaks have been reported in many countries and are listed as a notifiable disease by the World Organization for Animal Health (OIE). ASF is an economically important swine disease. The clinical signs, which can vary between hyperacute and acute, are typical hemorrhagic symptoms similar to those of classical swine fever, salmonellosis, or erysipelas (Agüero et al., 2003; Zsak et al., 2005; Pérez-Filgueira et al., 2006). ASF is highly contagious and has a high mortality rate in swine populations without vaccination (Hess, 1981; Ley et al., 1984). ASF transmission in the African continent generally falls under three categories of epidemiology cycles (Penrith et al., 2004): 1) a sylvatic cycle of maintenance involving warthogs (Phaecochoerus africanus) and ticks of the genus Ornithodoros (infected ticks bite domestic pigs); 2) a tick-pig cycle, in which ASF virus (ASFV) is transmitted via tick to pigs in their dwellings; and 3) a domestic pig cycle incorporating horizontal transmission (this cycle is restricted only to pig populations). Furthermore, the swill from consuming infected pork products can also become a source of transmission, such as was evident in an outbreak in Portugal (Manso Ribeiro et al., 1958).

ASFV was first reported in 1921 in Kenya (Montgomery, 1921), and has since spread throughout most sub-Saharan Africa countries where it now remains endemic in central, eastern, and southern Africa (El-Hicheri et al., 1998; Penrith et al., 2004). Outbreaks have expanded to both the mainland and islands such as Madagascar (Roger et al., 2001) and Mauritius (Lubisi et al., 2009). The highest distribution of ASFV was found in central and eastern Africa (Lubisi et al., 2005). The disease has become widespread, ranging from western Africa to the Iberian Peninsula. Outside the African continent, the first case was found in Portugal in 1957 (Manso Ribeiro et al., 1958). Subsequently, outbreaks have been reported in several European countries (Spain, Belgium, France, Italy, Malta, Andorra, and the Netherlands) (Penrith et al., 2004), Caribbean countries (Cuba, Dominican Republic, and Haiti) (Wilkinson, 1989; Seifert, 1996), Brazil (Lyra, 2006), Caucasus countries (Georgia, Armenia, and Azerbaijan) (Rowlands et al., 2007), and in several territories in Russia (Beltrán-Alcrudo et al., 2008).

ASF is caused by ASFV, in genus Asfivirus of family Asfarviridae (Dixon et al., 2000). The ASFV genome varies in size between 170 and $190 \mathrm{~kb}$ (Dixon, 1988; Boom et al., 1990). Laboratory diagnosis is the first criterion to provide reliable disease identification. However, it has not been possible to distinguish the different serotypes of ASF. Therefore, the major grouping of genotypes is critical to molecular epidemiological clarification. Molecular diagnosis provides robust detection and differentiation of ASFV genotypes using polymerase chain reaction (PCR) amplification and nucleotide sequencing (Chou, 1992; Bastos et al., 2003). These techniques not only assist the differentiation of ASF from other hemorrhagic diseases but also define the genotypes and molecular epidemiology (Bastos et al., 2003). The comparison of ASFVs based on the partial sequence of the $p 72$ or $B 646 \mathrm{~L}$ gene has allowed the identification of inter-strain variation level (López-Otin et al., 1990; Yu et al., 1996). Twentytwo genotypes have been previously described, with the major genotype groups distinguished 
using the most variable locus based on the $\mathrm{C}$-terminal end of the $p 72$ gene sequence (major capsid structural gene), and serving as the reference identification (Bastos et al., 2003; Lubisi et al., 2005; Boshoff et al., 2007). Subsequently, these genotypes have been clearly classified into four major lineages using approximately $400 \mathrm{bp}$ of $p 72$ sequence (Michaud et al., 2013).

The objectives of this study were to provide a simple and useful ASFV diagnosis method using PCR-based sequencing and to assess the epidemiological patterns and the geographic origin of the outbreak. We also established an efficient framework for phylogeographic comparison of ASFV based on smaller fragments of $p 72$ gene sequences than were used in previous studies. The significance of this study is to provide practical diagnosis from degraded DNA or putrefied samples.

\section{MATERIAL AND METHODS}

\section{DNA samples}

ASFV sequences $(\mathrm{N}=516)$ based on the partial $\mathrm{C}$-terminal $p 72$ gene region were compiled from GenBank. The geographic origin of each sequence was recorded for epidemiologic study. Overall, the sequences were derived from various countries at different times of isolation, which could be divided into four locations, including African, European, and Caribbean countries and Brazil, as well as Caucasus countries and Russian territories.

The ASFV sequences were isolated from countries in Africa that included Angola ( $\mathrm{N}$ $=3)$, Benin $(\mathrm{N}=7)$, Botswana $(\mathrm{N}=2)$, Burkina Faso $(\mathrm{N}=2)$, Burundi $(\mathrm{N}=5)$, Cameroon ( $\mathrm{N}$ $=11)$, Cape Verde $(\mathrm{N}=2)$, Democratic Republic of the Congo $(\mathrm{N}=5)$, Gambia $(\mathrm{N}=1)$, Ghana $(\mathrm{N}=5)$, Ivory Coast $(\mathrm{N}=6)$, Kenya $(\mathrm{N}=80)$, Madagascar $(\mathrm{N}=1)$, Malawi $(\mathrm{N}=32)$, Mauritius $(\mathrm{N}=5)$, Mozambique $(\mathrm{N}=21)$, Namibia $(\mathrm{N}=21)$, Nigeria $(\mathrm{N}=26)$, Republic of Congo $(\mathrm{N}=5)$, Senegal $(\mathrm{N}=1)$, South Africa $(\mathrm{N}=61)$, Tanzania $(\mathrm{N}=34)$, Togo $(\mathrm{N}=1)$, Uganda $(\mathrm{N}=$ 49), Zambia $(\mathrm{N}=44)$, and Zimbabwe $(\mathrm{N}=7)$. European countries were composed of Belgium $(\mathrm{N}=1)$, France $(\mathrm{N}=1)$, Holland $(\mathrm{N}=1)$, Italy $(\mathrm{N}=17)$, Malta $(\mathrm{N}=1)$, Portugal $(\mathrm{N}=13)$, and Spain $(\mathrm{N}=20)$. Caribbean countries and Brazil included Brazil $(\mathrm{N}=3)$, Dominican Republic $(\mathrm{N}=2)$, and Haiti $(\mathrm{N}=2)$. The Caucasus countries and Russia territories were comprised of Armenia $(\mathrm{N}=1)$, Azerbaijan $(\mathrm{N}=2)$, Georgia $(\mathrm{N}=3)$, Iran $(\mathrm{N}=1)$, Russia $(\mathrm{N}=10)$, and the Ukraine $(\mathrm{N}=1)$. The accession number and isolated place of each sequence in this study are summarized in Table S1.

\section{Sequences analysis}

All ASFV sequences were analyzed using two pairs of primers to identify the regions of interest based on a partial fragment of the $p 72$ gene sequence. The first pair of primers was recommended by OIE as a TaqMan PCR protocol for detection of the ASFV genome (King et al., 2003). The PCR product of the first pair of primers was $250 \mathrm{bp}$ in length (205 bp without the primer sequences), contained within the 478-bp PCR fragment of the second pair of primers (440 bp without the primer sequences) (Bastos et al., 2003). The outer pair of primers was shown to exhibit the ability to indicate the 22 different genotypes divided into four major lineages as referred to in a broad study (Bastos et al., 2003; Michaud et al., 2013).

We investigated the comparative phylogenetic analysis between results from amplification by the outer and inner pairs of primers using bioinformatics. Nomenclature of each 
new individual genotype in our studies used Arabic numerals followed by English letters. The number of genotypes was tracked against a previous study that used Roman numerals (Bastos et al., 2003). The analysis of DNA polymorphism was calculated using DnaSP v5 (Librado and Rozas, 2009). Phylogenetic analysis was performed using the lowest Bayesian information criterion scores and corrected Akaike information criterion to describe the best substitution pattern. The phylogenetic tree was reconstructed using a neighbor-joining tree with the maximum likelihood statistical method (Felsenstein, 1981; Saitou and Nei, 1987) in the CLUSTALW algorithm with default parameters (Thompson et al., 1994) via MEGA5 (Tamura et al., 2011). The node reliability was assessed by 10,000 bootstraps. The medianjoining network relationship was constructed via NETWORK 4.6.1.1 (Bandelt et al., 1999).

\section{RESULTS}

Comparative phylogenetic analysis of the 205-bp inner fragment of the ASFV $p 72$ gene yielded 44 individual genotypes. No insertions or deletions were found in this fragment, as had been found for the outer fragment. Forty-six polymorphic sites were identified with 20 singleton variable sites and 26 parsimonious informative sites (Table S2). Furthermore, the amino acid sequence alignment showed 11 polymorphisms. Nucleotide diversity was 0.04325 \pm 0.00231 . The composition of $\mathrm{G}+\mathrm{C}$ content was 0.447 .

The phylogenetic reconstruction using a neighbor-joining tree with the maximum likelihood statistical method and Kimura 2-parameters with a discrete gamma distribution $(+\mathrm{G})$ at the 5 rate categories generated the best phylogenetic tree. The nucleotide analysis of the products generated using the inner primers was similar to the 22 major genotypes identified following amplification using the outer primers. Slight differences were found between those that included genotype 20a and genotypes XX and XXI, genotype 1a and genotypes I and XVII, and genotype 11a and genotypes XI and XII (Figure 1). The four clades were identified with poor bootstrapping support. These results also showed the ability to indicate the four major lineages as did the study using the outer primers (Michaud et al., 2013). Using a median-joining NETWORK provided valuable phylogeographic information based on the inner fragment (Figure 2). In the African continent, multi-individual genotypes were related to geographical region. The results were divided into four phylogeographic areas.

Clade A was found in the central and eastern parts of Africa. The main genotype populations were found in Kenya, Uganda, and Burundi. Some isolation from the Republic of the Congo and the Democratic Republic of the Congo could be observed. Tanzania had multigenotypes that included genotypes $9 \mathrm{a}, 10 \mathrm{~h}$, and $10 \mathrm{i}$ that showed close relationship between Clades A and B (Table S3 $)$. Clade B was only distributed in eastern Africa, with the exception of some isolated instances of genotype 8a that occurred in multiple countries in both eastern and southern Africa. Clade $\mathrm{C}$ was identified in both eastern and southern Africa. Interestingly, genotypes 1a and 2a, belonging to Clade $\mathrm{C}$, showed widespread distribution of ASFV not only within the African continent, but also within Europe and other continents. The route of transmission of genotype 1a was via a western route from Africa and Europe through the Caribbean countries and Brazil. Genotype 2a spread out of the African continent via Madagascar and Mauritius to trans-Caucasus countries and the Russian Federation. The major genotypes of clade D were found in the southern part of Africa; however, within this clade, genotypes 5a, $5 \mathrm{~b}$, and $6 \mathrm{a}$ were found in Mozambique and Malawi. 


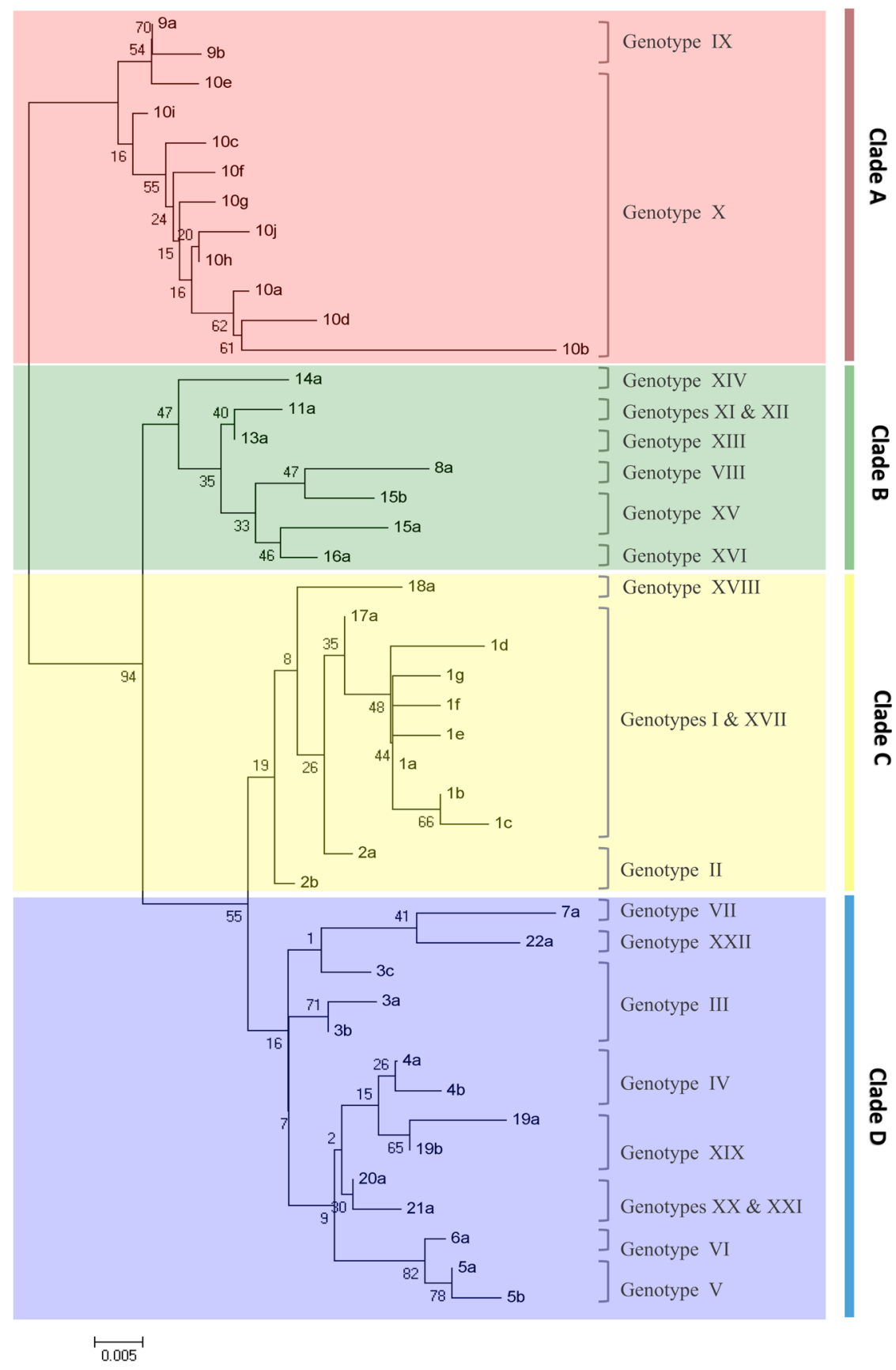

Figure 1. Comparative phylogenetic analysis between the 205-bp (Arabic numerals with English letters) and 440-bp (Roman numerals) $p 72$ genes of African swine fever virus. All nodes were supported by bootstrap values $(10,000$ replicates). Scale bar corresponds to nucleotide substitutions per sites. 


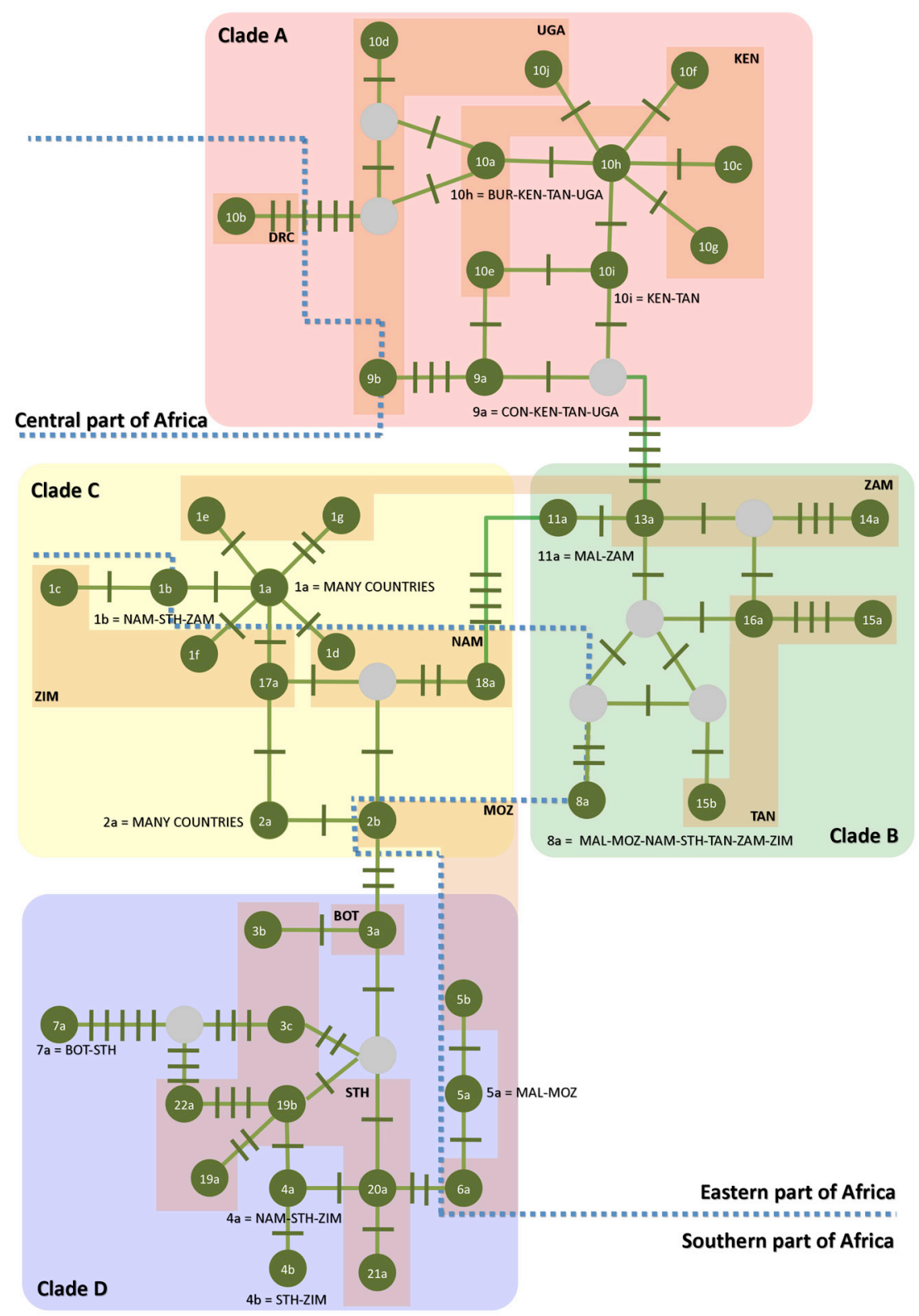

Figure 2. Median-joining NETWORK analysis revealed the 44 groups of African swine fever virus (ASFV) based on the 205-bp $p 72$ gene of ASFV. The Arabic numerical plus English lettering inside each green circle represents individual genotypes. The gray circles signify a mutated position whereas the cross marks across the connecting lines refer to number of nucleotide substitutions between genotypes. Blue dotted lines refer to the borderline of each African region. $\mathrm{CON}=$ Republic of Congo; DRC $=$ Democratic Republic of the Congo; KEN = Kenya; UGA $=$ Uganda; $\mathrm{BUR}=$ Burundi; TAN = Tanzania; ZAM = Zambia; $\mathrm{MAL}=$ Malawi; $\mathrm{MOZ}=$ Mozambique; $\mathrm{ZIM}=$ Zimbabwe; NAM = Namibia; $\mathrm{STH}=$ South Africa; BOT = Botswana . 


\section{DISCUSSION}

Using results from amplification of an inner fragment representing partial $p 72$ gene sequences, phylogenetic analysis divided the population genotypes of ASFV into four clades. Comparison between the analysis from use of outer and inner primer pairs yielded somewhat similar results. Despite poor bootstrapping support derived from the phylogenetic analysis based on the inner primer sequences, the fur major lineages could be clearly identified as shown in an earlier study (Michaud et al., 2013). Our protocol could be robustly applied to track individual genotype origin. The 205 nucleotides serve as a molecular tool not only for ASFV diagnosis but also to provide its epidemiological history. From the analysis of phylogeographic-related genetic variation, the four clades were shown to be derived from 44 genotypes that showed sporadic patterns in the African continent, and the traditional distribution patterns were identified, including the western route of genotype 1a as well as the eastern route of genotype 2a, both of which spread out of Africa. A widespread association of the four clades with irregular outbreaks was found in several countries among central, southern, and eastern Africa (Table S3).

Clade A was distributed in a restricted manner around the central and upper parts of eastern Africa: Kenya, Uganda, Burundi, the Republic of the Congo, and the Democratic Republic of the Congo. In Tanzania, some genotypes of clade A were observed: genotypes 9a, 10h, and 10i. We believed that these genotypes might have spread from clade A to Tanzania. Strong evidence for this hypothesis includes the first report of genotype 9a in Tanzania in 2005 and the later genotype, 10i, in 2009. Furthermore, genotype 10h was initially described from Phaecochoerus porcus in Kenya in 1959 (Bastos et al., 2003), and later in Tanzania in the 1960s, 1980s, and 2000s. Clade B was identified from an endemic area of the outbreak in the eastern Africa: Tanzania, Zambia, Malawi, and Mozambique. Interestingly, genotype 8a in clade B exhibited high transmission among various countries along eastern and southern Africa. However, in the last decade, this genotype has mostly vanished.

Clade $\mathrm{C}$ was found in both eastern and southern Africa. The traditional genotypes 1a and 2a, which had spread around the world as referenced in many previous studies, belonged to this clade. The genotype 1a epidemiology had been first recorded by GenBank in Portugal. This was the first outbreak of ASFV in the European continent, occurring in 1957 (Bastos et al., 2003). Its epidemiology was believed to originate from Kenya in eastern Africa. Afterward, it was dispersed in most sub-Saharan African countries and then was distributed out of Africa (Bastos et al., 2003; Penrith et al., 2004). It had been reported in European and Iberian peninsular countries. This genotype was transmitted across the Atlantic Ocean through several Caribbean countries and Brazil. In contrast, genotype 2a was first recorded in 1991 from Zambia (Lubisi et al., 2005), and then spread through Mozambique (Bastos et al., 2004) and to the island countries comprising Madagascar (Roger et al., 2001) and Mauritius (Lubisi et al., 2009). Afterward, it was distributed out of the African continent. The first report of its re-introduction was confirmed in the Caucasus countries in 2007, including Georgia and Armenia, and in several territories in Russia (Rowlands et al., 2007; Chapman et al., 2008; Malogolovkin et al., 2012). An outbreak had been reported from Azerbaijan in 2008 and Iran in 2009 (Rahimi et al., 2010). Recently, according to Gallardo et al. (2014) this genotype was also reported in Ukraine (JX857521). Lastly, clade D could be classified into two groups, including the main populations in the southern Africa (southern group) and the genotypes 5a, 5b, and 6a in Mozambique and Malawi (eastern group). 
Recently, the rapid spread of ASFV has placed ASF-free countries around the world at risk. These results could generate safe and useful molecular diagnosis tools for ASFV epidemiological pattern determination. Use of the short $p 72$ sequence provides advantage over the longer 440-bp fragment, in particular, for use in degraded DNA or putrefied samples. The significance of this study from a phylogeographic perspective is to identify the origin of viral outbreaks, facilitating the decision planning required to limit their spread. Furthermore, integration between our study and information on alternative genes such as the hypervariable central variable region could potentially provide additional valuable tools for future epidemiological assessment and intra-genotypic relationships among the ASFV genotypes.

\section{ACKNOWLEDGMENTS}

Research supported by "assistantships" from the Faculty of Veterinary Medicine, Kasetsart University, Thailand. The authors are grateful to Associate Professor Patamabhorn Amavisit and Assistant Professor Tanu Pinyopummintr for providing useful guidance on the original manuscript. We also have special thanks for our colleagues, Ms. Worata Klinsawat and Ms. Waradee Buddhakosai for their comments and preparation of the manuscript.

\section{$\underline{\text { Supplementary material }}$}

\section{REFERENCES}

Agüero M, Fernández J, Romero C, Sánchez Mascaraque C, et al. (2003). Highly sensitive PCR assay for routine diagnosis of African swine fever virus in clinical samples. J. Clin. Microbiol. 41: 4431-4434.

Bandelt HJ, Forster P and Röhl A (1999). Median-Joining networks for inferring intraspecific phylogenies. Mol. Biol. Evol. 16: 37-48.

Bastos ADS, Penrith ML, Crucière C, Edrich JL, et al. (2003). Genotyping field strains of African swine fever virus by partial p72 gene characterization. Arch. Virol. 148: 693-706.

Bastos ADS, Penrith ML, Macome F, Pinto F, et al. (2004). Co-circulation of two genetically distinct viruses in an outbreak of African swine fever in Mozambique: no evidence for individual co-infection. Vet. Microbiol. 103: 169182.

Beltrán-Alcrudo D, Lubroth J, Depner K and De La Rocque S (2008). African swine fever in the Caucasus. FAO Empres Watch 1-8. Available at [www.fao.org/3/a-aj214e.pdf].

Boom R, Sol CJ, Salimans MM, Jansen CJ, et al. (1990). Rapid and simple method for purification of nucleic acids. $J$. Clin. Microbiol. 28: 495-503.

Boshoff CI, Bastos ADS, Gerber LJ and Vosloo W (2007). Genetic characterization of African swine fever viruses from outbreaks in south Africa (1973-1999). Vet. Microbiol. 121: 45-55.

Chapman DAG, Tcherepanov V, Upton C and Dixon LK (2008). Comparison of the genome sequences of non-pathogenic and pathogenic African swine fever virus isolates. J. Gen. Virol. 89: 397-408.

Chou S (1992). Molecular epidemiology of envelope glycoprotein H of human cytomegalovirus. J. Infect. Dis. 166: 604-607.

Dixon LK (1988). Molecular cloning and restriction enzyme mapping of an African swine fever virus isolate from Malawi. J. Gen. Virol. 69: 1683-1694.

Dixon LK, Costa JV, Escribano JM, Rock DL, et al. (2000). Virus taxonomy: The classification and nomenclature of viruses. In: Seventh Report of the International Committee on Taxonomy of Viruses (Van Regenmortel MHV, Fauquet CM, Bishop DHL, Carestens EB, et al., eds.) Academic Press, London, 159-165.

El-Hicheri K, Gomez-Tejedor C, Penrith ML, Davies G, et al. (1998). The 1996 epizootic of African swine fever in the Ivory Coast. Rev. Sci. Tech. 17: 660-673.

Felsenstein J (1981). Evolutionary trees from DNA sequences: a maximum likelihood approach. J. Mol. Evol. 17: 368-376. Gallardo C, Fernández-Pinero J, Pelayo V, Gazaev I, et al. (2014). Genetic variation among African swine fever genotype II viruses, Eastern and Central Europe. Emerg. Infect. Dis. 20: 1544-1547.

Hess WR (1981). African swine fever: a reassessment. Adv. Vet. Sci. Comp. Med. 25: 39-69. 
King DP, Reid SM, Hutchings GH, Grierson SS, et al. (2003). Development of a TaqMan PCR assay with internal amplification control for the detection of African swine fever virus. J. Virol. Methods 107: 53-61.

Ley V, Almendral JM, Carbonero P, Beloso A, et al. (1984). Molecular cloning of African swine fever virus DNA. Virology 133: 249-257.

Librado P and Rozas J (2009). DnaSP v5: a software for comprehensive analysis of DNA polymorphism data. Bioinformatics 25: 1451-1452.

López-Otin C, Freije JMP, Parra F, Mendez E, et al. (1990). Mapping and sequence of the gene coding for protein $\mathrm{p} 72$, the major capsid protein of African swine fever virus. Virology 175: 477-484.

Lubisi BA, Bastos ADS, Dwarka RM and Vosloo W (2005). Molecular epidemiology of African swine fever in East Africa. Arch. Virol. 150: 2439-2452.

Lubisi BA, Dwarka RM, Meenowa D and Jaumally R (2009). An investigation into the first outbreak of African swine fever in the Republic of Mauritius. Transbound. Emerg. Dis. 56: 178-188.

Lyra TM (2006). The eradication of African swine fever in Brazil, 1978-1984. Rev. Sci. Tech. 25: 93-103.

Malogolovkin A, Yelsukova A, Gallardo C, Tsybanov S, et al. (2012). Molecular characterization of African swine fever virus isolates originating from outbreaks in the Russian Federation between 2007 and 2011. Vet. Microbiol. 158: 415-419.

Manso Ribeiro J, Rosa Azevedo JA, Texeira MJO, Braco Forte MC, et al. (1958). An atypical strain of swine fever virus in Portugal/Peste porcine africaine provoquée par une souche different (Souche L) de la souche classique. Bull. Off. Int. Epiz. 50: 516-534.

Michaud V, Randriamparany T and Albina E (2013). Comprehensive phylogenetic reconstructions of African swine fever virus: proposal for a new classification and molecular dating of the virus. PLoS One 8: e69662.

Montgomery RE (1921). On a form of swine fever occurring in British East Africa (Kenya Colony). J. Comp. Pathol. Ther. 34: 159-191.

Penrith ML, Thomson GR and Bastos ADS (2004). African swine fever. In: Infectious diseases of livestock. 2nd edn. (Coetzer JAW and Tustin RC, eds.). Oxford University Press, Cape Town, 1087-1119.

Pérez-Filgueira DM, González-Camacho F, Gallardo C, Resina-Talaván P, et al. (2006). Optimization and validation of recombinant serological tests for African swine fever diagnosis based on detection of the p30 protein produced in Trichoplusia ni larvae. J. Clin. Microbiol. 44: 3114-3121.

Rahimi P, Sohrabi A, Ashrafihelan J, Edalat R, et al. (2010). Emergence of African swine fever virus, Northwestern Iran. Emerg. Infect. Dis. 16: 1946-1948.

Roger F, Ratovonjato J, Vola P and Uilenberg G (2001). Ornithodoros porcinus ticks, Bushpigs, and African swine fever in Madagascar. Exp. Appl. Acarol. 25: 263-269.

Rowlands RJ, Michaud V, Heath L, Hutchings G, et al. (2007). African swine fever virus isolate, Georgia, 2007. Emerg. Infect. Dis. 14: 1870-1874.

Saitou N and Nei M (1987). The neighbor-joining method: a new method for reconstructing phylogenetic trees. Mol. Biol. Evol. 4: 406-425.

Seifert HSH (1996). Tropical Animal Health. 2nd edn. Kluwer Academic Publishers, Dordrecht.

Tamura K, Peterson D, Peterson N, Stecher G, et al. (2011). MEGA5: molecular evolutionary genetics analysis using maximum likelihood, evolutionary distance, and maximum parsimony methods. Mol. Biol. Evol. 28: 2731-2739.

Thompson JD, Higgins DG and Gibson TJ (1994). CLUSTAL W: improving the sensitivity of progressive multiple sequence alignment through sequence weighting, position-specific gap penalties and weight matrix choice. Nucleic Acids Res. 22: 4673-4680.

Wilkinson PJ (1989). African swine fever virus. In: Virus infections of vertebrates: Virus infections of porcines (Penjaert MB, ed.), Elsevier, Amsterdam, 17-35.

Yu M, Morrissy CJ and Westbury HA (1996). Strong sequence conservation of African swine fever virus p 72 protein provides the molecular basis for its antigenic stability. Arch. Virol. 141: 1795-1802.

Zsak L, Borca MV, Risatti GR, Zsak A, et al. (2005). Pre-clinical diagnosis of African swine fever in contact-exposed swine by a real-time PCR assay. J. Clin. Microbiol. 43: 112-119. 